Research Article

\title{
New Definition of Ultrafine Particles in Mine Paste and Its Relationship with Rheological Properties
}

\author{
Jincheng Xie, Dengpan Qiao $(\mathbb{D}$, Runsheng Han, Tao Deng, and Jun Wang \\ Kunming University of Science and Technology, Kunming 650000, Yunnan, China \\ Correspondence should be addressed to Dengpan Qiao; 20030033@kust.edu.cn
}

Received 25 February 2021; Revised 6 April 2021; Accepted 20 April 2021; Published 3 May 2021

Academic Editor: Tingting Zhang

Copyright (C) 2021 Jincheng Xie et al. This is an open access article distributed under the Creative Commons Attribution License, which permits unrestricted use, distribution, and reproduction in any medium, provided the original work is properly cited.

\begin{abstract}
Mine backfill paste is generally composed of tailings and coarse aggregates. In engineering practice, the definitions in fill material classification are vague. In this paper, the size range of ultrafine particles is defined by the Stokes sedimentation test and hydraulic coarseness method. The size range of ultrafine particles is affected not only by the geometric size of the particles but also by the physical characteristics of the particles themselves. This definition has more comprehensive considerations and stricter physical and mathematical significance than the traditional definition of ultrafine particles based only on size. There is a strong correlation between ultrafine particles in fill materials and the rheological properties of the mine backfill paste. In this study, through experiments and correlation analysis, it was found that the content of ultrafine particles is positively correlated with the plastic viscosity of the mine backfill paste, and its growth range is exponential. The coarse aggregate content is positively correlated with the yield stress of the mine backfill paste. A regression analysis model was established for the rheological properties of mine backfill paste. The model has few factors and high correlation, so it can simply and efficiently predict the rheological properties of mine backfill paste and guide engineering practice.
\end{abstract}

\section{Introduction}

Mine backfill paste is often made by mixing coarse aggregate, tailings, cement, and water. Many studies on the rheological properties of mine backfill paste mention that ultrafine particles have a significant influence on the rheological properties of the paste. However, there is no unified scientific and objective basis for the definition of ultrafine particles. In the study of sediment, particles with a particle size less than $0.01 \mathrm{~mm}$ are called fine particles, which is more accurate in academic research [1]. There is no strict definition of fine-grained tailings in the mining industry. Yin et al. [2] thought that the average particle size is less than $0.03 \mathrm{~mm}$, and tailings with a particle size less than $0.019 \mathrm{~mm}$ and content greater than $10 \%$ are called fine-grained tailings. Researchers studying mine backfill paste think that the paste can only be formed if the content of under- $20 \mu \mathrm{m}$ particles is not less than $15 \%$. Many studies $[3,4]$ show that under-
$20 \mu \mathrm{m}$ particle content has a significant impact on paste fluidity, and the paste has better fluidity when under- $20 \mu \mathrm{m}$ content is $15-20 \%$. Wang et al. [5] studied the influence of different particle size ranges on the slurry bleeding rate by uniform design. The test results showed that tailing particles with a particle size of $20-37 \mu \mathrm{m}$ had the greatest influence on the slurry bleeding rate. $\mathrm{Wu}$ et al. [6] said that the average particle size of ultrafine tailings is less than $30 \mu \mathrm{m}$, with the content of particles below $19 \mu \mathrm{m}$ more than $50 \%$, the content of particles above $37 \mu \mathrm{m}$ less than $30 \%$, and the content of particles above $74 \mu \mathrm{m}$ less than $10 \%$. Kang et al. [7] used the L-tube model to measure and calculate the flow parameters of the filling slurry in the Duda lead-zinc mine. The results showed that, within a certain range, increasing the under$20 \mu \mathrm{m}$ fine particles is beneficial to improve the fluidity of the slurry. $\mathrm{Xu}$ et al. [8] tested the rheological properties of gangue filling slurry with different gradation aggregates, and the results showed that particles from 0 to $30 \mu \mathrm{m}$ had the 
greatest influence on the rheological properties of the slurry. In a study of the particle flocculation mechanism, Mehta [9] said that the boundary between sticky and nonsticky particles should be $20 \mu \mathrm{m}$. Viscous particles significantly influence the formation of the slurry flocculation structure.

In conclusion, many studies in the literature have pointed out that the content of ultrafine particles has an important influence on the rheological properties of paste. A size of $20 \mu \mathrm{m}$ is often used as the dividing line for the ultrafine particle size range, with particles smaller than $20 \mu \mathrm{m}$ used as ultrafine particles. However, the reason why $20 \mu \mathrm{m}$ is used as the dividing line has not been clearly pointed out in the literature, and there is no clear theoretical derivation, only empirical limits were obtained through many experiments. There are significant differences in apparent density, particle size distribution, and shape sizes of different mine filling materials. If only the particle size is used for demarcation, it seems that the classification criteria are too singular, unscientific, and objective. In engineering practice, due to the improvement of mineral processing technology, most mine tailings have reached the category of "mud" in soil mechanics. It is urgent to make a scientific and systematic definition of the size of ultrafine particles and clarify their physical conditions to study the influence of ultrafine particles on the rheological properties of paste more scientifically and systematically.

\section{Definition of Ultrafine Particles}

The research object of this paper is ultrafine particles, and the main research aspect is the rheological properties of mine backfill paste, so the hydrodynamic performance of particles in water should be studied. Cement is usually used as the cementing material in the mine backfill paste, and cement in powder form undergoes a hydration reaction in water to form cement floc, which is a network or chain polymer with irregular shape, but it is still the finest particle in the mine backfill paste, that is, the slowest settling particle in the filling material. The authors think that the settling velocity of ultrafine particles in water should be similar to or the same as that of cement floc; that is, the maximum hydraulic roughness of cement floc should be regarded as the demarcation standard for ultrafine particles.

In the definition of ultrafine particles, it is necessary to measure the hydraulic coarseness of cement flocs, which is measured by the sedimentation balance method in this paper. The basic principle of the settling balance method is to calculate the particle size distribution of particles by measuring the mass of the particles settled in the liquid medium at different times $[10,11]$. Its main feature is that the particles are not affected by ultrasound, stirring, and other factors in the measurement process, and the method does not destroy the structure of the particles or break up flocs. It is based on the Stokes principle: the correlation between settling velocity and particle size is as follows:

$$
v_{x}=\frac{g\left(\rho_{s}-\rho_{w}\right) X^{2}}{18 \eta}
$$

where $v_{x}$ is the settling velocity, $\rho_{s}$ and $\rho_{w}$ are the densities of powder and water, respectively, $X$ is the diameter of the spherical particles, and $\eta$ is the viscosity of the liquid medium (usually water or another pure viscous fluid). From this formula, it can be seen that the settling velocity is proportional to the diameter of the particles. The larger the diameter, the faster the settling velocity, and the smaller the diameter, the slower the settling velocity. The expression of particle diameter can be obtained from the following:

$$
X=\sqrt{\frac{18 \eta v_{x}}{g\left(\rho_{s}-\rho_{w}\right)}}
$$

where $X$ represents the Stokes diameter, and its physical meaning is the diameter of a sphere with the same settling velocity as particles of this size. Therefore, the diameter obtained by the Stokes sedimentation method is also called the effective diameter.

A schematic diagram of the settlement balance method is shown in Figure 1.

After time $t_{i}$, the effective mass $m_{i}$ of particles settling on the tray is

$$
m_{i}=M \int_{X_{i}}^{X_{\max }} f_{(X)} d_{X}+\int_{X_{\min }}^{X_{i}} \frac{v t_{i}}{H} f_{(X)} d_{X},
$$

where $M$ is the total theoretical mass on the settling balance, $H$ is the settling height, that is, the distance from the settling balance to the liquid level, and $f_{(X)}$ is the particle size distribution frequency function. $X_{i}$ is the critical Stokes particle size corresponding to $t_{i}$ time; that is, after $t_{i}$ time, only the particles with particle size greater than or equal to $X_{i}$ finish settling, and the rest remain in the liquid phase. According to formula (2), the calculation formula is as follows:

$$
X=\sqrt{\frac{18 \eta H / t_{i}}{g\left(\rho_{s}-\rho_{w}\right)}}
$$

Therefore, the particle size distribution can be calculated by measuring the $m_{i}-t_{i}$ curve, combined with formulas (3) and (4).

However, if the above method is to be extended to the measurement of floc gradation, appropriate changes must be made because the cement powder will undergo a hydration reaction in water, which will cause the density of the floc to change. Second, floc particles are nonstrict spheres, and the concept of an equivalent sphere should be used to replace floc particles equivalently.

First, the Stokes principle is used to analyze the force of the floc, as shown in Figure 2. Flocculant moves at a uniform speed because of its balanced force in water, which is affected by three forces: gravity, buoyancy, and viscous resistance.

Therefore, through the analysis,

$$
G=F_{V}+F_{b} \text {. }
$$

At the same time, according to the concept of equivalent spheres and the Stokes viscous resistance formula, 


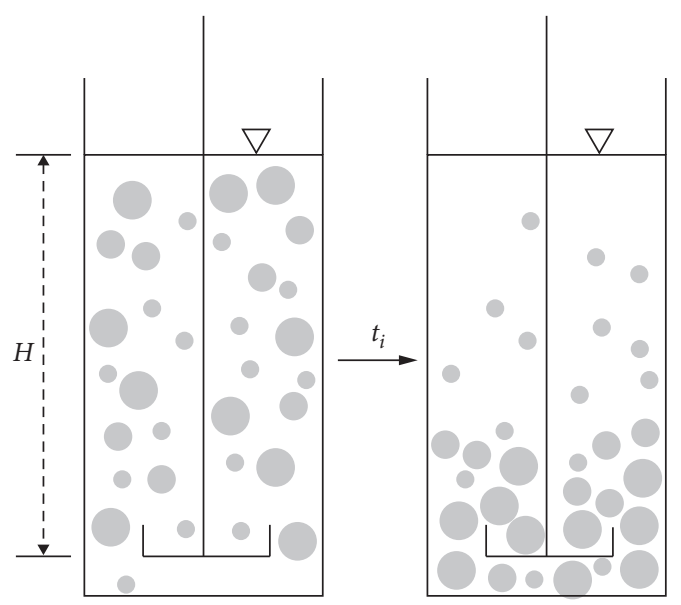

FIGURE 1: Schematic diagram of the settlement balance method.

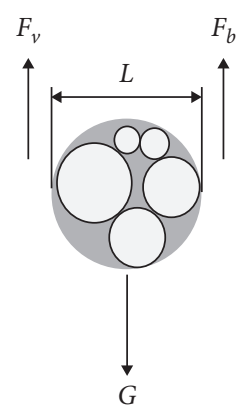

Figure 2: Force analysis of flocculation microbeads.

$$
\begin{aligned}
G & =\frac{4}{3} \pi \rho_{S} g a^{3}+\rho_{w} v_{\text {viod }} g \\
F_{b} & =\frac{4}{3} \pi \rho_{w} g a^{3}+\rho_{w} v_{\text {viod }} g \\
F_{V} & =3 \pi \eta L v_{L}, \\
L & =(\beta+1)^{1 / 3} * 2 a .
\end{aligned}
$$

Based on the above four formulas, the settling velocity of flocs can be obtained:

$$
v_{L}=\frac{2 g\left(\rho_{s}-\rho_{w}\right) a^{2}}{9 \eta(\beta+1)^{1 / 3}} .
$$

It can be seen from the above formula that the sedimentation rate of floc is similar to Stokes sedimentation, which depends on the particle size of the floc equivalent sphere. The larger the particle size, the faster the sedimentation rate, and the smaller the particle size, the slower the sedimentation rate. However, it is noted that there is still a basic water demand rate $\beta$ in the above formula, which should be considered in the experimental analysis. According to formula (7), the $m_{i}-t_{i}$ curve can be measured by the sedimentation balance method, and the particle size distribution of flocs can be calculated.
The equivalent particle size formula of the floc is

$$
a_{i}=\sqrt{\frac{(\beta+1)^{1 / 3} \times 18 \eta H / t_{i}}{g\left(\rho_{s}-\rho_{w}\right)}} .
$$

The equivalent particle size distribution function of the floc can be obtained according to the above formula and the measured $m_{i}-t_{i}$ curve.

2.1. Measurement Test of Cement Floc Gradation. Equations (7) and (8) can effectively measure the equivalent ball gradation of floc. The test device used in the test is shown in Figure 3. Its main components are the precision balance, boom, settling tray, and beaker. The suspender is connected to the weight of the balance to transfer the mass of the settling pan to the balance. The mass reduced by the weight of the balance is the mass of floc settlement increased in the settling pan. The mass-time curve of the balance can be recorded in real time to measure the floc gradation.

The specific steps of the test are as follows: (1) remove $20 \mathrm{~g}$ of slurry from the slurry test and put it into a settling beaker and inject a certain amount of water into the beaker for dilution so that the volume of water in the beaker reaches a fixed value, the purpose of which is to ensure that the settling height is consistent every time. (2) Stir the liquid in the beaker to make the flocs disperse evenly. (3) Place the settling tray at the bottom of the beaker. (4) With the boom connected to the balance, start the measurement program to record the curve of the balance quality as it changes with time. The test device is shown in Figure 3.

\subsection{Experimental Results and Analysis of Floc Gradation.} The floc gradation was measured using the test scheme. The sedimentation rate and time curve is shown in Figure 4 using a water-cement ratio of $1: 1$ as an example. The cumulative floc sedimentation rate first increased rapidly with time and then slowed. This occurs because large particles have a very fast sedimentation rate, and the cumulative sedimentation rate reached approximately $40 \%$ in only one second, with the diameter of the floc settled at this time larger than $100 \mu \mathrm{m}$. Next, the sedimentation rate of the floc began to decrease gradually, which was due to the diameter of the floc beginning to decrease, and the sedimentation rate reached $70 \%$ within approximately $50 \mathrm{~s}$, when the diameter of the floc in the water was less than $5 \mu \mathrm{m}$. Then, the sedimentation rate decreased further until $200 \mathrm{~s}$, when the sedimentation rate reached more than $90 \%$, and there was almost no floc in the water.

The floc gradation curve was obtained by calculation, and the particle size distribution curves with different watercement ratios $(1: 1,1.6: 1$, and $2: 1)$ are shown in Figure 5 .

As shown in Figure 5, the floc particle size is mainly distributed between 10 and $100 \mu \mathrm{m}$, and the particle size of 1 to $10 \mu \mathrm{m}$ accounts for a small part; the floc particle size increased from the minimum to about $80 \mu \mathrm{m}$, and its particle size frequency began to decrease, then the floc particle content gradually decreased, and finally the floc particle size reached less than $200 \mu \mathrm{m}$. 


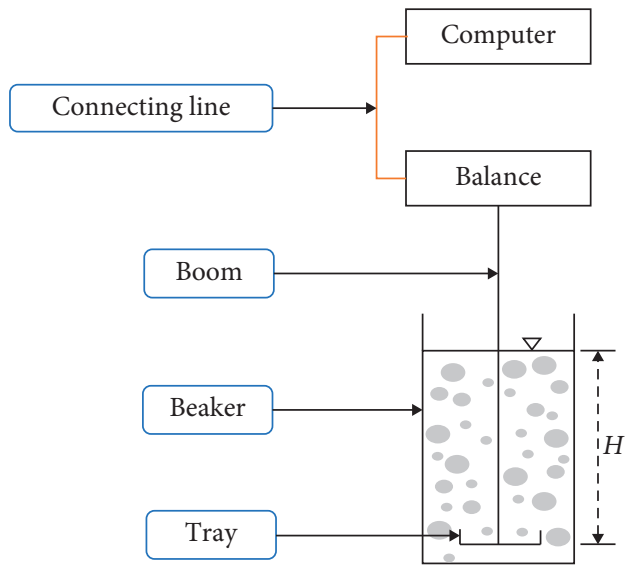

Figure 3: Settlement balance test.

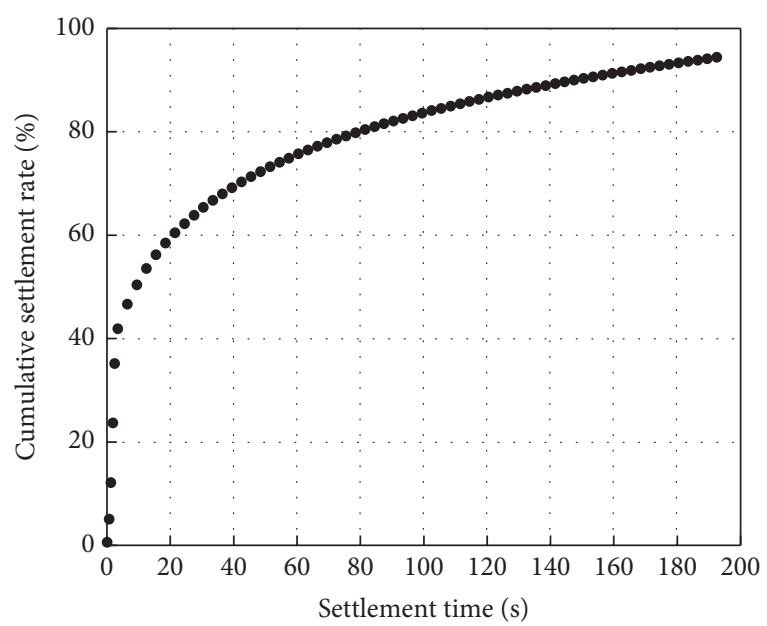

Figure 4: Sedimentation curve of flocculated microbeads.

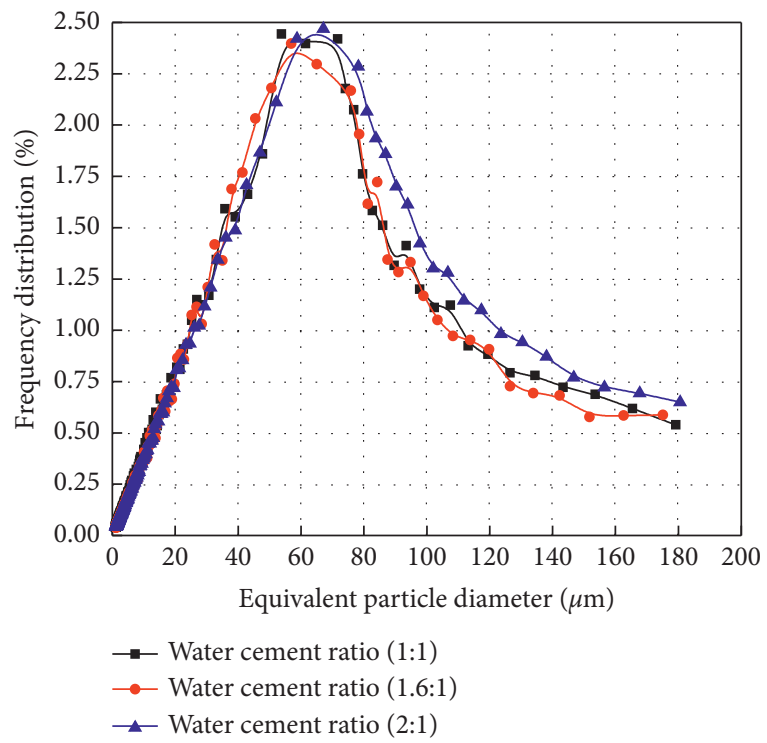

FIgURE 5: Gradation curve of flocculated microbeads.
Importantly, for mine backfill paste, the mass ratio of cement to water is generally above $1: 1$, which means that the volume of water is more than three times that of the cement powder, and the content of water in the mortar is far greater than that of cement. Under this condition, the distribution trend and content of the floc gradation are almost unchanged under three different water-cement ratios. It is noted that with the increase of the water-cement ratio, the curve shifts, but the amplitude is very small. Overall, the three sets of curves are almost at the same level, so it seems that they are within the mortar ratio range of paste. In essence, this is because the cement content in the mortar is small, and many gaps remain between floc particles after the cement hydration reaction is completed. However, due to the relatively large water content in mortar, the change in water quantity has little influence on the particle size of the floc equivalent sphere.

The results of the floc gradation test show that the particle size of floc is mainly distributed between 10 and $100 \mu \mathrm{m}$, and the particle size of 1 to $10 \mu \mathrm{m}$ accounts for a small part; when the floc size reaches about $80 \mu \mathrm{m}$, its frequency begins to decrease, then gradually decreases, and finally the floc size reaches less than $200 \mu \mathrm{m}$. More than $99 \%$ of flocs have a Stokes particle size within $200 \mu \mathrm{m}$, so the boundary Stokes particle size of the flocs is $200 \mu \mathrm{m}$. Then, taking the Stokes particle size of $200 \mu \mathrm{m}$ as the boundary condition, the ultrafine tailings particles should have a matching settling velocity (the liquid medium is water or pure viscous fluid), and on this basis, their mechanical effects in the movement process are the same.

Assuming that the settling velocity of cement floc with the largest Stokes equivalent particle size is $v_{x}$, the settling velocity of tailings in water should satisfy the following formula:

$$
v_{x} \geq \frac{g\left(\rho_{p}-\rho_{w}\right) X^{2}}{18 \eta} .
$$

From this, the following formula is derived:

$$
X \leq \sqrt{\frac{18 \eta v_{x}}{g\left(\rho_{p}-\rho_{w}\right)}}
$$

where $\eta$ is the viscosity of water, $\rho_{p}$ is the apparent density of the tailings, and $\rho_{W}$ is the apparent density of water. Substitute the settlement velocity formula of cement floc to obtain

$$
X \leq \sqrt{\frac{8 \times 10^{-6}\left(\rho_{s}-\rho_{w}\right)}{(\beta+1)^{1 / 3}\left(\rho_{p}-\rho_{w}\right)}} .
$$

As shown in formula (11), the particle size range of ultrafine tailings is related to the density of water tailings, flocs, and the basic water demand rate of flocs. Compared with the definition of ultrafine tailings by most scholars, the particle size of ultrafine tailings is no longer a fixed particle size range but rather changes with the apparent density of the tailings. 
The old and new definitions of ultrafine particles of waste rock and wind sand in Jinchuan are compared in Table 1. Under the old definition, the content of ultrafine waste rock and wind sand particles is $2 \%$, so the two kinds of filling materials cannot be distinguished from the content of ultrafine particles. Thus, the numerical relationship between ultrafine particle content and rheological properties cannot be determined from the relationship. The new definition of ultrafine particles effectively avoids this problem. In the new definition, the content of ultrafine particles in waste rock and river sand is different, and there is a significant gap to conform to the facts. This proves that the new definition of ultrafine particles has wider applicability.

\section{Rheological Test of Mine Backfill Paste}

This paper mainly studies the relationship between ultrafine particles and the rheological properties of mine backfill paste. After ultrafine particles were defined, the rheological properties of the mine backfill paste with different filler ratios were evaluated by rheological testing.

The RheoCAD500 concrete rheometer produced in France was used in the test, as shown in Figure 6. The rheometer has two modes: manual control and program control. In manual mode, the torque or speed can be adjusted as required. The program control mode can be used with either a fast scheme or an expert scheme, which can be selected for torque or speed, respectively. The fast scheme is used to identify the maximum torque of the paste. The logarithmic curve of the shear rate and shear stress is first decreased and then increased, with the number and duration of each step programmed. The advantage of this program is that it does not need to know the sample well and will automatically identify the rotation speed corresponding to the required maximum torque. The expert scheme is flexible and can be set according to needs for the loading step time, but it does not provide the corresponding maximum speed under a given torque.

The double helix (1\#) rotor was selected for the test. The internal program of the computer was set to increase the rotor speed from $0 \mathrm{rpm}$ to $250 \mathrm{rpm}$ and then decrease it from 250 to $0 \mathrm{rpm}$. There were 100 speed points in total. Each speed point lasted for $5 \mathrm{~s}$, with the data at each $1 \mathrm{~s}$ interval averaged.

Expert mode was used in the study to detect the process of the paste changing from a solid state to a fluid state. The loading and thixotropic control of the RheoCAD500 rheometer is shown in Figure 7.

To ensure the rotor was covered with paste, the volume of paste added was from $30 \mathrm{~mm}$ to the top of the rotor and $30 \mathrm{~mm}$ from the bottom of the rotor. Temperature has a significant influence on rheological characteristics. To eliminate this influence, the test temperature was controlled at $20^{\circ} \mathrm{C}$. The rheological test scheme of the mine backfill paste is shown in Table 2, where the mine backfill paste used in the test met the limit concentration condition of the paste, and the paste was homogeneous and had no segregation.
3.1. Basic Physical Parameters of Filling Materials. In this study, the crushed waste rock aggregate and desert sand of the Jinchuan Company were selected as filling aggregate for research. The basic physical parameters of waste rock and wind sand are shown in Table 3.

According to the safety technical standards for cemented filling, the maximum particle size of cemented filling aggregate should not exceed $1 / 5$ of the conveying pipe diameter. Most conveying pipes in the Jinchuan Mine stope are steel pipes or plastic pipes with an inner diameter of $150 \mathrm{~mm}$, so the maximum particle size of waste rock should not exceed $20 \mathrm{~mm}$. Broken waste rock aggregate with a maximum particle size of $12 \mathrm{~mm}$ was used in this project. The gradation or particle size distribution of crushed stone aggregate is an important property of aggregate that determines the packing density of the aggregate, amount of filling cement, and pipe transportation performance.

It can be seen from Table 4 that the maximum size of the waste stone was $12 \mathrm{~mm}$. Approximately, $50 \%$ of the waste stone was above $4.75 \mathrm{~mm}$, and approximately, $70 \%$ was above $2.36 \mathrm{~mm}$. The coarse particle content was too high and the fine material content was too low for the coarse particles to be suspended.

Desert sand is a natural aggregate collected naturally. For example, in desert areas, it is an ideal filling material with spherical particles and 90\% quartz sand. See Tables 5 and 6 for the physical parameters of desert sand. The chemical composition of sand is shown in Table 5.

It can be seen from the above that desert sand is mainly $\mathrm{SiO}_{2}$, and the content of $\mathrm{SiO}_{2}$ is higher than that of the other four materials in the table, which are inert materials.

It can be seen from Table 6 that desert sand is less than $1.18 \mathrm{~mm}$, with a particle size distribution characterized as "fewer coarse particles, more middle particles, and fewer fine particles." Approximately, 50\% of the desert sand had a grain size below $0.3 \mathrm{~mm}$, and more than $99 \%$ had a grain size below $0.6 \mathrm{~mm}$. The content of the fine portion is too high, but the content of the coarse material is too small.

According to the definition of ultrafine particles, the particle size and content of ultrafine particles of waste rock and wind sand are calculated, and the results are shown in Table 7.

As shown in Table 7 , the ultrafine particle content of desert sand is $31 \%$ and that of waste rock is $9 \%$.

\section{Influence of Aggregate Gradation on Rheological Parameters}

The rheological properties and the Herschel-Bulkley (H-B) model of the waste rock-desert sand paste with different concentrations, cement contents, and proportions were obtained by rheological tests. The rheological parameters were mainly affected by paste properties such as concentration and cement content. Most studies have shown that the proportion of thick and thin parts of filling aggregate also significantly affects the rheological parameters of mine backfill paste. 
TABle 1: Comparison of new and old definitions of ultrafine particles.

\begin{tabular}{lcc}
\hline Type & Ultrafine particle content (old definition) (\%) & Ultrafine particle content (new definition) (\%) \\
\hline Waste rock (Jinchuan) & 2 & 9 \\
River sand (Jinchuan) & 2 & 14.9 \\
\hline
\end{tabular}
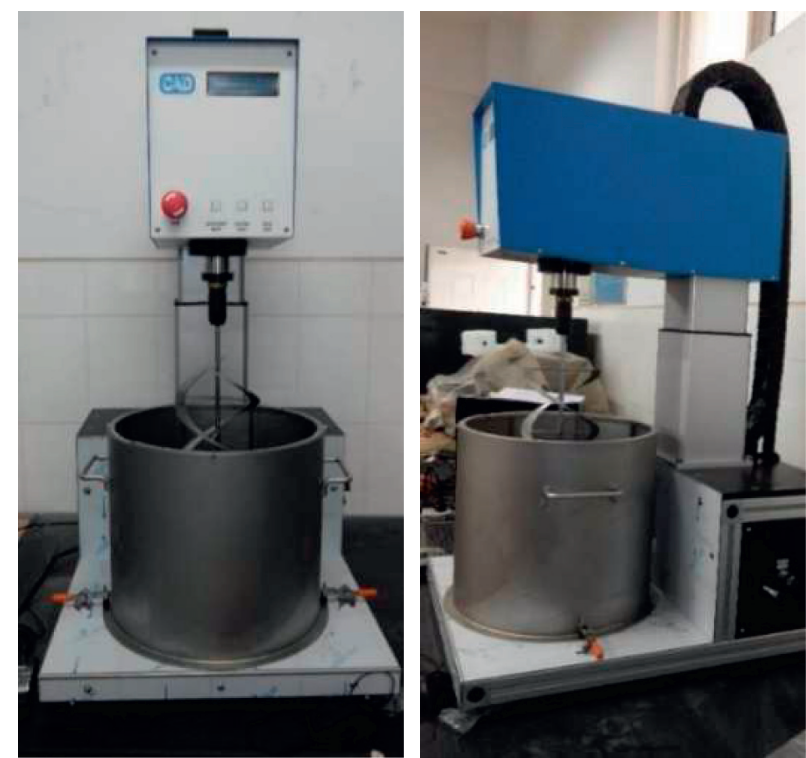

Figure 6: RheoCAD500 rheometer.

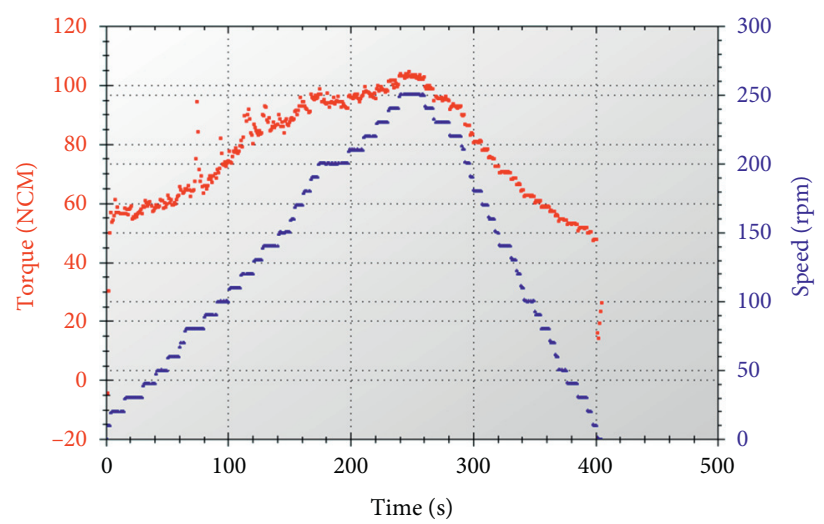

FIgURE 7: Loading and thixotropic control of the RheoCAD500 rheometer.

TABLE 2: Rheological test of paste filling material.

\begin{tabular}{lcccc}
\hline Type of aggregate & Aggregate gradation & Mass concentration (\%) & Amount of cement added $\left(\mathrm{kg} / \mathrm{m}^{3}\right)$ & Rheological parameters \\
\hline \multirow{3}{*}{ Waste rock-desert sand } & $5: 5$ & & \\
& $6: 4$ & $78,79,80,81,82,83,84$ & $240,260,280,310$ \\
\hline
\end{tabular}

4.1. Effect of Ultrafine Particles on Plastic Viscosity of Paste. Most studies show that the proportion of ultrafine content in mine backfill paste has a significant influence on the fluidity of the mine backfill paste. The ultrafine tailing content (excluding cement flocs) in the mine backfill paste and the plastic viscosity of mine backfill paste are plotted as follows:

As shown in Figure 8, the influence of the ultrafine aggregate content on the plastic viscosity of the mine backfill 
TABle 3: Physical parameters of filling aggregate.

\begin{tabular}{lccccc}
\hline Type of aggregate & Density $\left(\mathrm{t} / \mathrm{m}^{3}\right)$ & Loose bulk density $\left(\mathrm{t} / \mathrm{m}^{3}\right)$ & Moisture content (\%) & Porosity (\%) & Compactness of stacking (\%) \\
\hline Waste rock & 2.625 & 1.623 & 1.255 & 40.4 & 59.6 \\
Desert sand & 2.570 & 1.519 & 0.219 & 40.9 & 59.1 \\
\hline
\end{tabular}

TABLE 4: Gradation of waste rock.

\begin{tabular}{lccccc}
\hline $\begin{array}{l}\text { Particle size } \\
(\mathrm{mm})\end{array}$ & $\begin{array}{c}\left(d_{i \max }+d_{\text {imin }}\right) / 2 \\
(\mathrm{~mm})\end{array}$ & $\begin{array}{c}\text { Frequency degree } \\
\text { distribution }(\%)\end{array}$ & $\begin{array}{c}\text { Negative accumulation } \\
\text { distribution }(\%)\end{array}$ & $\begin{array}{c}\text { Fuller distribution } \\
(\%)\end{array}$ & $\begin{array}{c}\text { Frequency } \\
\text { difference }\end{array}$ \\
\hline $9.5-12$ & 10.75 & 10.62 & 100 & 100.00 & -12.32 \\
$4.75-<9.5$ & 7.125 & 37.97 & 89.38 & 57.06 & 15.34 \\
$2.36-<4.75$ & 3.555 & 20.67 & 51.41 & 34.43 & 4.65 \\
$1.18-<2.36$ & 1.77 & 7.17 & 30.74 & 27.23 & -4.00 \\
$0.6-<1.18$ & 0.89 & 7.57 & 23.57 & 19.36 & -0.30 \\
$0.3-<0.6$ & 0.45 & 5.03 & 10.97 & 13.69 & -0.64 \\
$0.15-<0.3$ & 0.225 & 2.43 & 8.54 & 9.68 & -1.58 \\
$0.075-<0.15$ & 0.1125 & 2.97 & 5.57 & 5.59 & -1.12 \\
$<0.075$ & 0.0375 & 5.57 & & -0.02 \\
\hline
\end{tabular}

TABle 5: Chemical composition of desert sand.

\begin{tabular}{cccccccccccc}
\hline Component & $\mathrm{SiO}_{2}$ & $\mathrm{MgO}$ & $\mathrm{Fe}_{2} \mathrm{O}_{3}$ & $\mathrm{SO} 3$ & $\mathrm{Al}_{2} \mathrm{O}_{3}$ & $\mathrm{CaO}$ & $\mathrm{Cr}_{2} \mathrm{O}_{3}$ & $\mathrm{Na}_{2} \mathrm{O}$ & $\mathrm{K}_{2} \mathrm{O}$ & $\mathrm{TiO}_{2}$ & $\mathrm{Others}$ \\
\hline Desert sand & 91.90 & 1.10 & 2.43 & - & 2.13 & 2.44 & - & - & - & - & - \\
\hline
\end{tabular}

TABLE 6: Gradation of desert sand.

\begin{tabular}{lccccc}
\hline $\begin{array}{l}\text { Particle size } \\
(\mathrm{mm})\end{array}$ & $\begin{array}{c}\left(d_{\text {imax }}+d_{\text {imin }}\right) / 2 \\
(\mathrm{~mm})\end{array}$ & $\begin{array}{c}\text { Frequency degree } \\
\text { distribution }(\%)\end{array}$ & $\begin{array}{c}\text { Negative accumulation } \\
\text { distribution }(\%)\end{array}$ & $\begin{array}{c}\text { Fuller distribution } \\
(\%)\end{array}$ & $\begin{array}{c}\text { Frequency } \\
\text { difference }\end{array}$ \\
\hline $0.6-1.18$ & 0.89 & 0.83 & 100 & 100.00 & -37.42 \\
$0.3-<0.6$ & 0.45 & 48.87 & 99.17 & 61.75 & 30.78 \\
$0.15-<0.3$ & 0.225 & 21.17 & 50.30 & 43.67 & 8.38 \\
$0.075-<0.15$ & 0.1125 & 21.13 & 29.13 & 30.88 & 8.08 \\
$<0.075$ & 0.0375 & 8.00 & 8.00 & 17.83 & -9.83 \\
\hline
\end{tabular}

TABLE 7: Range and content of ultrafine particles of fill aggregate.

\begin{tabular}{lccc}
\hline Type of aggregate & Apparent density $\left(\mathrm{kg} / \mathrm{m}^{3}\right)$ & Size range of ultrafine particles $(<\mu \mathrm{m})$ & Content of ultrafine particles $(\%)$ \\
\hline Desert sand & 2570 & 120 & 31 \\
Waste rock & 2625 & 118 & 9 \\
\hline
\end{tabular}

paste is the same at different graduations. With an increase in ultrafine aggregate content, the plastic viscosity of the mine backfill paste increases, and given the same gradation, the increasing trend of different cement contents is approximately the same, which shows that the ultrafine particle content is undoubtedly the main factor affecting the plastic viscosity of the mine backfill paste.

It is noted that the absolute plastic viscosity is different with different cement contents, and it is obvious from the figure that the plastic viscosity of the mine backfill paste increases with an increase in cement content (given the same ultrafine particle content), which means that the cement content is also a factor affecting the plastic viscosity of the mine backfill paste. Therefore, a comparison chart of the relationship between the ultrafine particle content (including cement, floc, and ultrafine tailings) and plastic viscosity of different grades is analyzed.

As shown in Figure 9, the ultrafine particle content is positively correlated with plastic viscosity, and the plastic viscosity increases with an increase in ultrafine particle content. At the same mass concentration, the ultrafine particle content determines the plastic viscosity. Given the same ultrafine particle content, the higher the mass concentration of the mine backfill paste, the higher the plastic viscosity. Different grades will also cause a change in plastic viscosity. The higher the waste rock content of the mine backfill paste, the lower the plastic viscosity at the same concentration. The higher the waste rock content, the fewer 


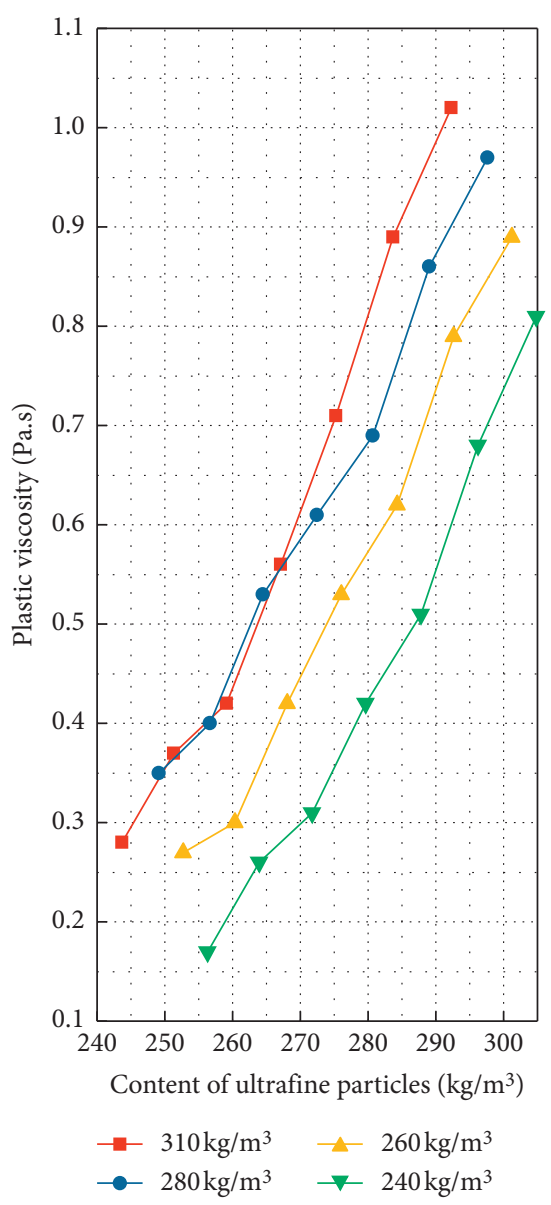

(a)

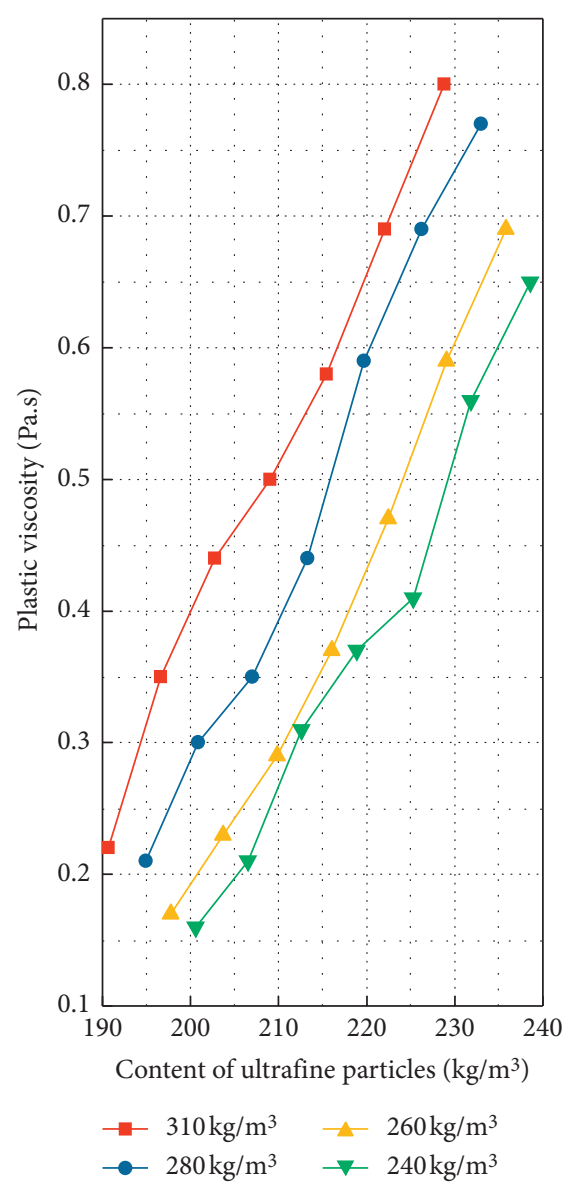

(b)

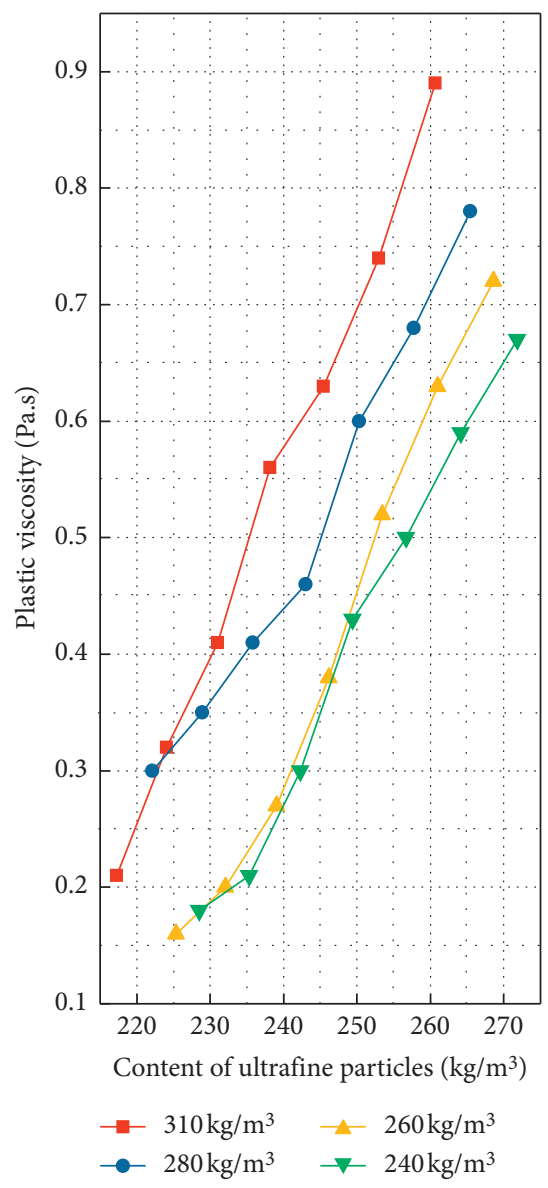

(c)

FIGURE 8: Relationship between the ultrafine tailing content and plastic viscosity under different gradations. (a) Waste rock : desert sand $=5$ : 5. (b) Waste rock: desert sand $=6: 4$. (c) Waste rock: desert sand $=7: 3$.

the ultrafine particles in the mine backfill paste, leading to a decrease in plastic viscosity.

Thus, it is not scientifically appropriate to use only the content of ultrafine particles as a factor to measure the change in plastic viscosity of the mine backfill paste. In the mine backfill paste, the most important condition for paste formation is the addition of water, which fills the pores between particles. Excess water maintains the movement transmission between particles. The addition of water causes paste flow and paste formation. Thus, the relationship between ultrafine particle content and water determines the plastic viscosity of the mine backfill paste. Therefore, the ratio of the mass of the ultrafine particles to the mass of the water is taken as a dependent variable, and the relationship between it and the plastic viscosity of the paste is examined by graphing it.

As shown in Figure 10, the ratio of the mass of the ultrafine particles to the mass of the water under different gradations is taken as the plastic viscosity of the paste as the dependent variable. The plastic viscosity of the paste increases exponentially with an increase in the ratio. Regression analysis of the data shows that the data conform to an exponential equation. Regression results show that the $R^{2}$ of the fitted curve is $94.13 \%$, and the correlation between factors is very high. The analysis of variance (Table 8 ) shows that the $F$ value of the regression curve is 4313, and the regression result of the equation is highly significant. Therefore, the ratio of ultrafine particles to water can be used as the standard to calculate and measure the plastic viscosity of mine backfill paste, which makes it more convenient to calculate and regress the plastic viscosity of the mine backfill paste.

\subsection{Effect of Coarse Aggregate Content on Yield Stress of Paste.} The rheological model of mine backfill paste meets the H-B model. It contains two important parameters: plastic viscosity and yield stress. Most studies show that the plastic viscosity of the paste is highly influenced by the fine particle content in the paste, while the yield stress is mostly influenced by the coarse aggregate in the paste.

To analyze the influence of the coarse aggregate in the paste on the plastic viscosity of the paste, the experimental data were plotted, taking the ratio of the coarse aggregate (aggregate larger than ultrafine particle size) to the water mass at the same gradation, different cement content, and different concentrations as independent variables and the 


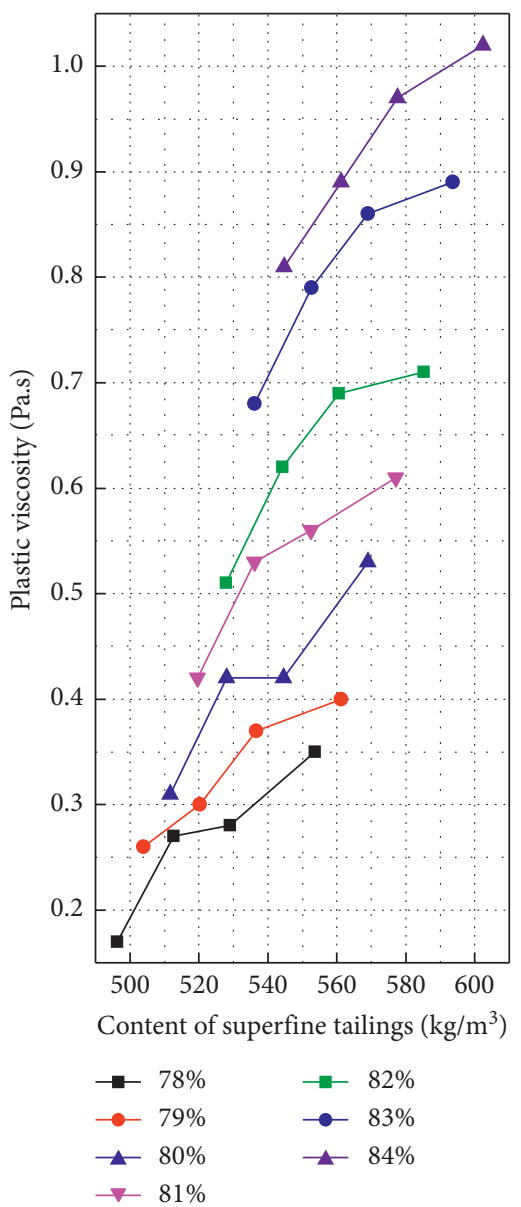

(a)
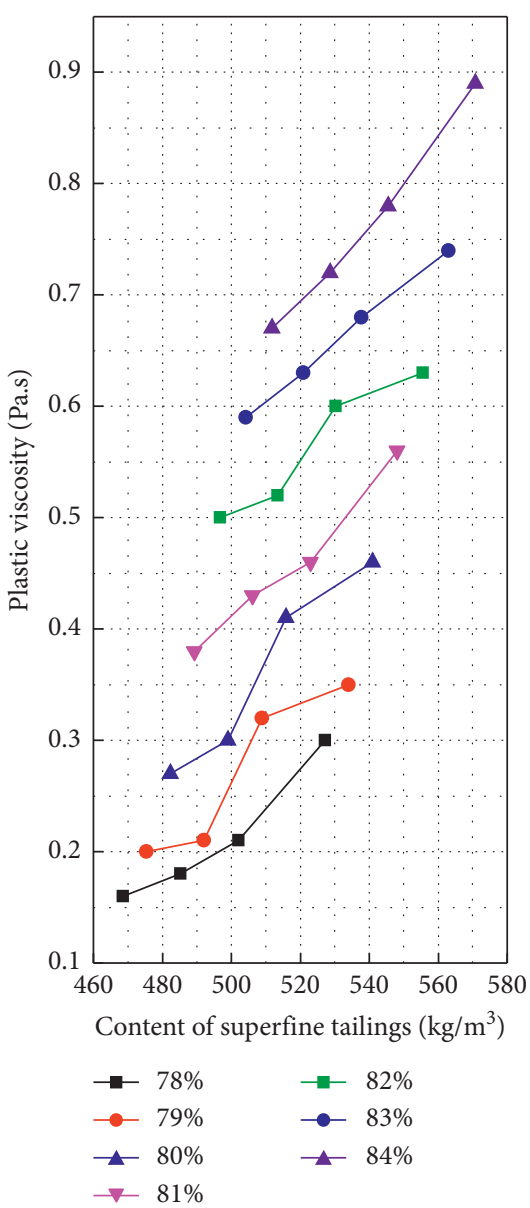

(b)

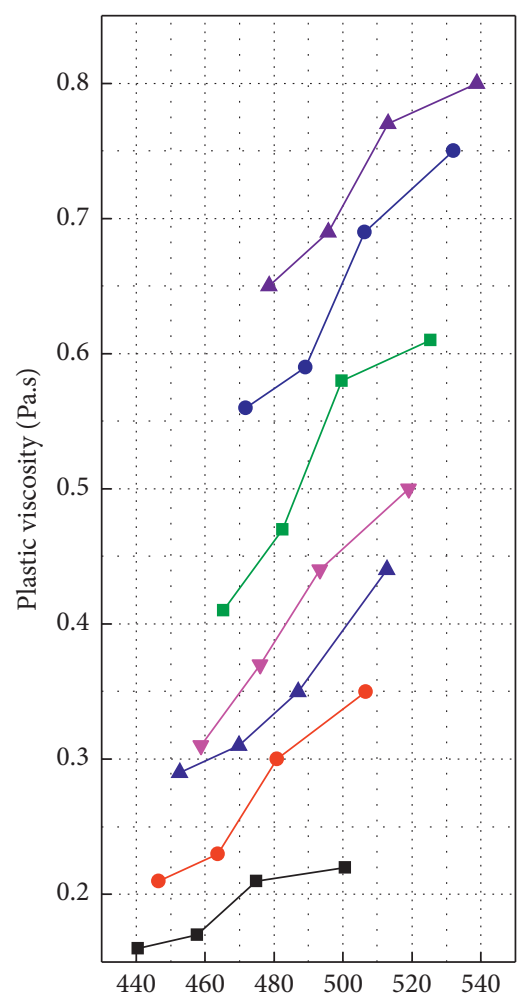

Content of superfine tailings $\left(\mathrm{kg} / \mathrm{m}^{3}\right)$

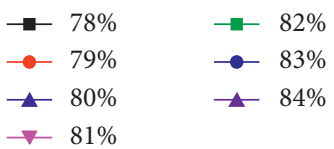

(c)

FIGURE 9: Relationship between ultrafine particle content and plastic viscosity at different gradations. (a) Waste rock: desert sand $=5: 5$. (b) Waste rock: desert sand $=6: 4$. (c) Waste rock : desert sand $=7: 3$.

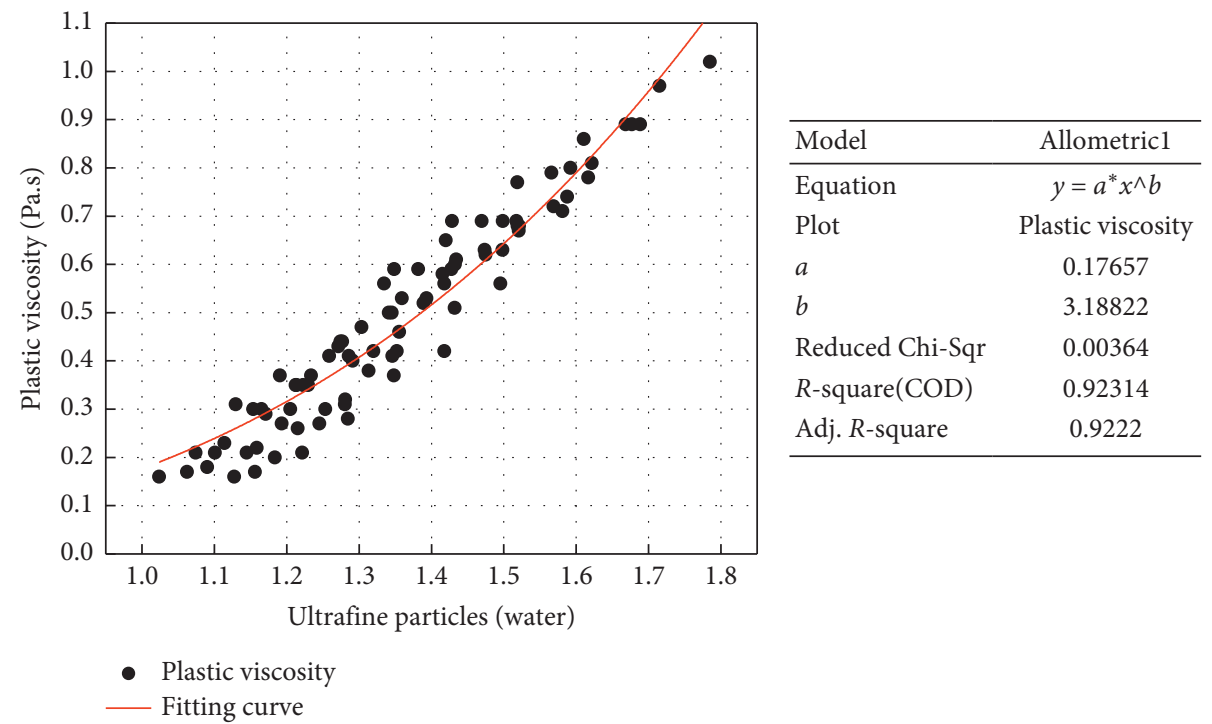

Figure 10: Relationship between the ratio of the mass of the ultrafine particles to the mass of the water and the plastic viscosity. 
TABle 8: ANOVA.

\begin{tabular}{lcccc}
\hline & DF & Sum of squares & Mean square & $F$ value \\
\hline Regression & 2 & 23.64582 & 11.82291 & 4313.05949 \\
Residual & 82 & 0.22478 & 0.00274 & \\
Uncorrected total & 84 & 23.8706 & & \\
Corrected total & 83 & 3.87821 & & \\
\hline
\end{tabular}

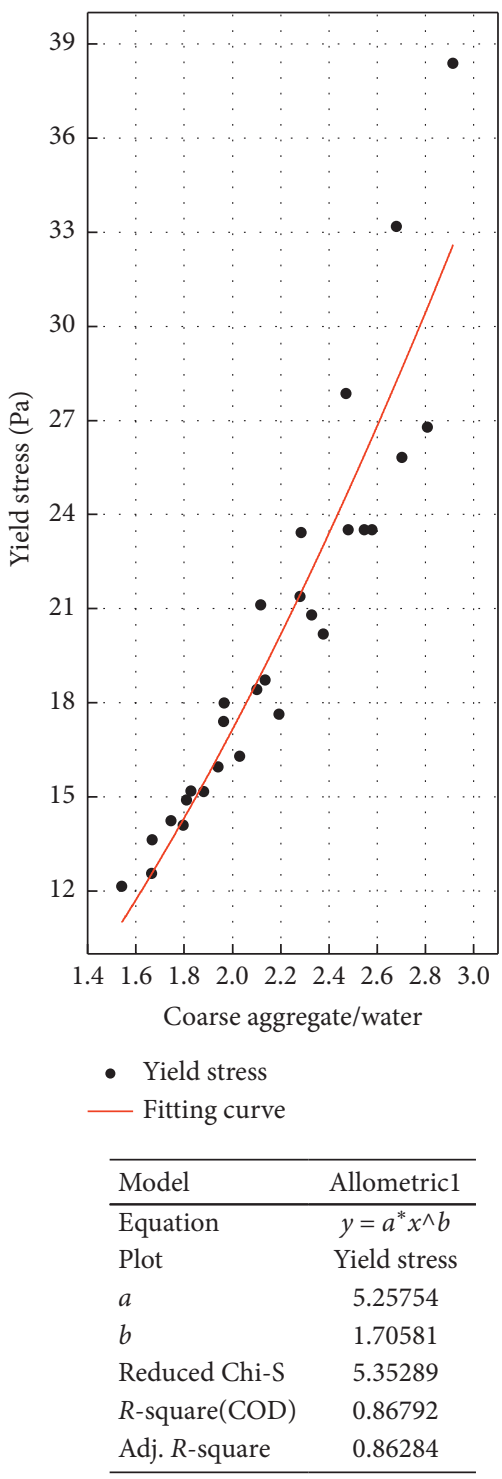

(a)

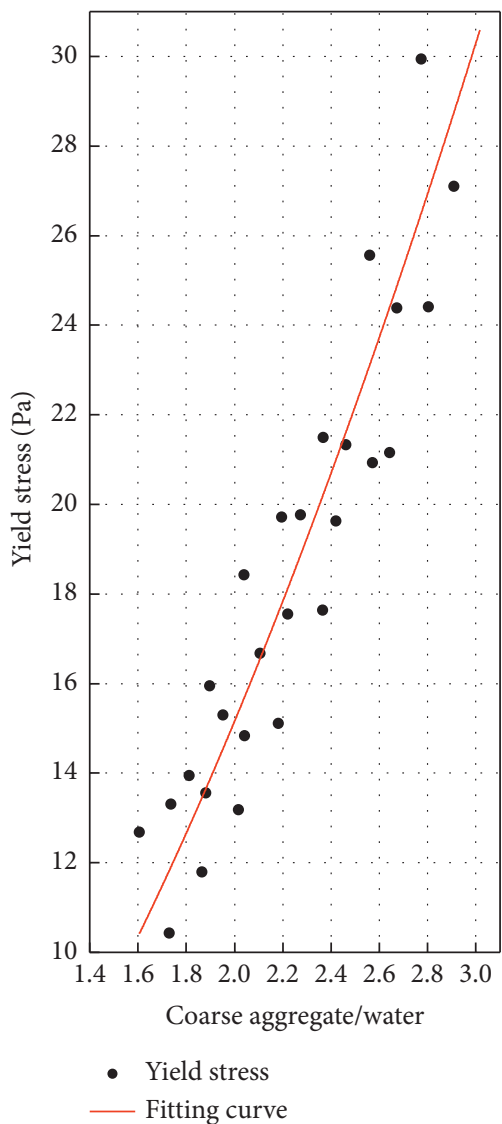

\begin{tabular}{lc}
\hline Model & Allometric1 \\
\hline Equation & $y=a^{*} x^{\wedge} b$ \\
Plot & Yield stress \\
$a$ & 4.63751 \\
$b$ & 1.70862 \\
Reduced Chi-S & 4.43518 \\
$R$-square(COD) & 0.874 \\
Adj. $R$-square & 0.86915
\end{tabular}

(b)

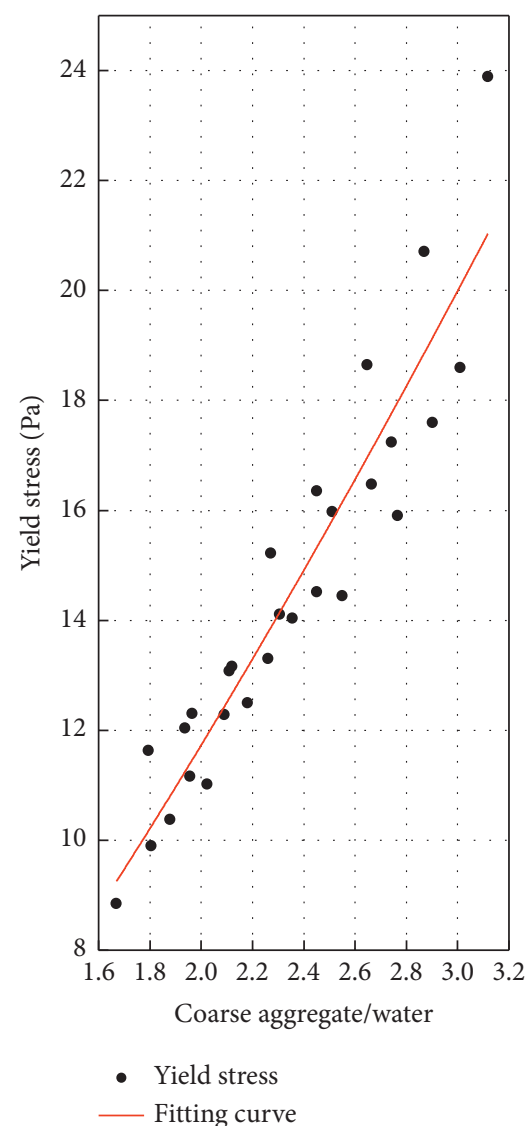

\begin{tabular}{lc}
\hline Model & Allometric1 \\
\hline Equation & $y=a^{*} x^{\wedge} b$ \\
Plot & Yield stress \\
$a$ & 4.71376 \\
$b$ & 1.31523 \\
Reduced Chi-Sqr & 1.40867 \\
$R$-square(COD) & 0.88439 \\
Adj. -square & 0.87995 \\
\hline
\end{tabular}

(c)

FIGURE 11: Relationship between the ratio of the mass of the coarse aggregate to the mass of the water and yield stress. (a) Waste rock: desert sand $=5: 5$. (b) Waste rock: desert sand $=6: 4$. (c) Waste rock: desert sand $=7: 3$.

yield stress of the mine backfill paste as the dependent variable.

As shown in Figure 11, the coarse aggregate content (aggregates larger than ultrafine particle size) in the waste rock-desert sand paste has a significant influence on the yield stress of the mine backfill paste. As shown in the figure, a change in coarse aggregate content causes a change in yield stress in the paste, and the ratio of coarse aggregate to water is positively correlated with yield stress; that is, an increase in coarse aggregate content leads to an increase in the yield stress of the paste. An increase in coarse aggregate content undoubtedly reduces the porosity of the paste and increases the possibility of friction between aggregates in the paste, which leads to an increase in the yield stress of the paste. The 
above relations exist and are obvious in waste rock-desert sand paste with different gradations.

The yield stress of the paste increases exponentially with an increase in the ratio of aggregate to mass in the paste. The regression equation of a $5: 5$ waste rock-desert sand ratio is $y=5.26 \times{ }^{1.71}, R^{2}=0.86$, the regression equation of a $6: 4$ waste rock-desert sand ratio is $y=4.64 \times{ }^{1.71}, R^{2}=0.87$, and the regression equation of a $7: 3$ waste rock-desert sand ratio is $y=4.71 \times{ }^{1.41}, R^{2}=0.88$. It can be seen from the above regression equations that the mass ratio of coarse aggregate to water can clearly characterize the yield stress of mine backfill paste with different proportions.

\section{Conclusion}

Mine backfill paste generally consists of tailings, coarse aggregate, cement, and water. In engineering practice, the definition of filling material classification is very vague. In this study, the size range of ultrafine particles was defined by the Stokes sedimentation test and hydraulic coarseness method. The relationship between ultrafine particles and the rheological properties of the paste was analyzed, and the following conclusions were obtained:

(1) The size range of ultrafine particles depends on the maximum hydraulic coarseness of the cement flocculation structure and the physical properties of the particles themselves. Within the range of the watercement ratio of mine backfill paste, the maximum hydraulic coarseness of the cement flocculation structure changes slightly, and the Stokes particle size of the floc is less than $200 \mu \mathrm{m}$. The range of ultrafine particles of fine aggregates, such as tailings, can be determined on this basis, which comprehensively considers the physical characteristics and size of particles and has relatively strict physical and mathematical definitions.

(2) There is a strong correlation between the ultrafine particle content in the mine backfill paste and the rheological properties of the mine backfill paste. The higher the ultrafine particle content, the greater the plastic viscosity of the mine backfill paste, with an exponentially increasing growth rate. The higher the coarse aggregate content, the greater the yield stress of the mine backfill paste. This conclusion is consistent with most studies in the literature. The mass ratio of ultrafine particle content to water content in paste reflects the amount of ultrafine particle content. The model of the rheological properties of waste rockdesert sand series paste is established by regression analysis. The model is simple, with few factors and high correlation. It can accurately predict the rheological properties of the mine backfill paste, which can be beneficial in guiding engineering practice.

\section{Data Availability}

All the data used to support this study are included within the article.

\section{Conflicts of Interest}

The authors declare that they have no conflicts of interest.

\section{References}

[1] Z. Zhu, T. Yang, M. Zhao et al., "Preliminary study on critical criteria of floc development and floc network development in cohesive fine sediment," Sediment Research, no. 1, pp. 20-25, 2009.

[2] G. Yin, X. Jing, W. Zuo'an et al., "Model test and field measurement of seepage characteristics of coarse and fine tailings dams," Chinese Journal of Rock Mechanics and Engineering, vol. 29, no. s2, pp. 3710-3718, 2010.

[3] M. Fall, J. Célestin, and H. F. Sen, "Potential use of densified polymer-pastefill mixture as waste containment barrier materials," Waste Management, vol. 30, no. 12, pp. 2570-2578, 2010.

[4] O. H. Wallevik and J. E. Wallevik, "Rheology as a tool in concrete science: the use of rheographs and workability boxes," Cement and Concrete Research, vol. 41, no. 12, pp. 1279-1288, 2011.

[5] H. Wang, A. Li, A. Wu et al., "New definition of paste based on full tailings gradation," Journal of Central South University (Natural Science Edition), no. 2, pp. 557-562, 2014.

[6] A. Wu, S. Yang, H. Wang et al., "Present situation and trend of ultra-fine paste disposal technology," Mining Technology, vol. 11, no. 3, pp. 4-8, 2011.

[7] R. Kang, P. Liang, and Z. Yao, "Study on fluidity of coarse aggregate filling slurry in Duda lead-zinc mine," Mining Research and Development, no. 3, pp. 14-18, 2017.

[8] W. Xu, B. Yang, S. Yang et al., "Experimental study on the correlation between rheological properties and particle size distribution of gangue filling slurry," Journal of Central South University (Natural Science Edition), vol. 47, no. 4, pp. 1282-1289, 2016.

[9] A. J. Mehta, "Problems in linking the threshold condition for the transport of cohesionless and cohesive sediment grain," Journal of Coastal Research, vol. 10, no. 1, pp. 170-177, 1994.

[10] H. Oshida, H. Masuda, K. Fukui et al., "Particle size measurement with an improved sedimentation balance method and microscopic method together with computer simulation of necessary sample size," Advanced Powder Technology, vol. 12, no. 1, pp. 79-94, 2001.

[11] K. Fukui, H. Yoshida, and T. Higashiguchi, "Effects of initial slurry concentration distribution on the particle size distribution measured with a sedimentation balance method," Advanced Powder Technology, vol. 15, no. 2, pp. 181-200, 2004. 